\title{
LOCAL EXCISION FOR EARLY RECTAL CANCER - IS IT PROPER SURGICAL DECISION?
}

\author{
Ignatov V., K. Ivanov, N. Kolev, A. Tonev, E. Kiryazov \\ Department of General and Operative Surgery, University Hospital "St. Marina”
}

\author{
Reviewed by: Prof. T. Temelkov
}

BACKGROUND: Sphincter preservation, disease control, and long-term survival are the main goals in the treatment of rectal cancer. Although transanal local excision is attractive because it is a sphincter sparing procedure, some contradictory data exist in the literature about its ability to locally control disease and provide overall survival comparable with radical procedures, even for patients with early stage tumor. In patients with early rectal cancer (T1), local excision may be an alternative approach in highly selected patients. For more advanced rectal cancer, radical surgical resection is the treatment of choice. METHODS: We reviewed the literature to identify the current recurrence and survival rates of both techniques as well as the salvage surgery success, only 1 study was prospective, 5 were comparative, and 5 were case reports. We present a case report of a woman with local excision of rectal tumor. Five years later a rectal recurrence has showed up. We describe the case and make some conclusions.

\section{INTRODUCTION}

Local excision of rectal neoplasms is well described as an alternative to abdominoperineal resection (APR) and anterior resection in selected patients, with fewer postoperative complications and operative mortality (1). Historically, local excision has included transanal (2), transsacral (3), and transsphincteric (4) approaches. The transanal approachis a minimally invasive technique that allows greater exposure and facility in the management of proximal disease than traditional local excision, with a shorter operative time and less morbidity than the radical surgical procedures (5). We found such data in the literature and sometimes provide this kind of treatment to our patients. But what we do indeed curative treatment or trying to avoid postoperative morbidity? According to the TNM staging system, the most valuable prognostic factor is the clinical stage (from I to IV). It has direct correlation with the presence or absence of local or distant metastases. Lymph node metastasis has been reported in $3 \%$ to $17 \%$ of T1 cancers (6-10) and is found in $52 \%$ of tumors $<5 \mathrm{~cm}(10)$. Features that increase the risk of lymph node metastasis include poor differentiation, vascular invasion, and depth of invasion (11). Low-risk T1 lesions (well or moderately well differentiated and without lymphatic invasion) carry a 5\% risk of lymph node metastasis, compared with $27 \%$ for high-risk lesions (12). A study report for $15 \%$ recurrence rate for locally resected adenomas (13).

We present a case of our practice with anamnesis for local excision of rectal cancer (pT1NxMx) in the past, 5 years

\section{Address for correspondence:}

Kr.Ivanov, Varna, 1 Hr. Smirnenski str,

University Hospital "St. Marina"

e-mail: teraton@abv.bg, kivanov@gisurgery.bg ago. On clinical examination, during routine follow-up procedure she was found to have a mass in the retrorectal re-

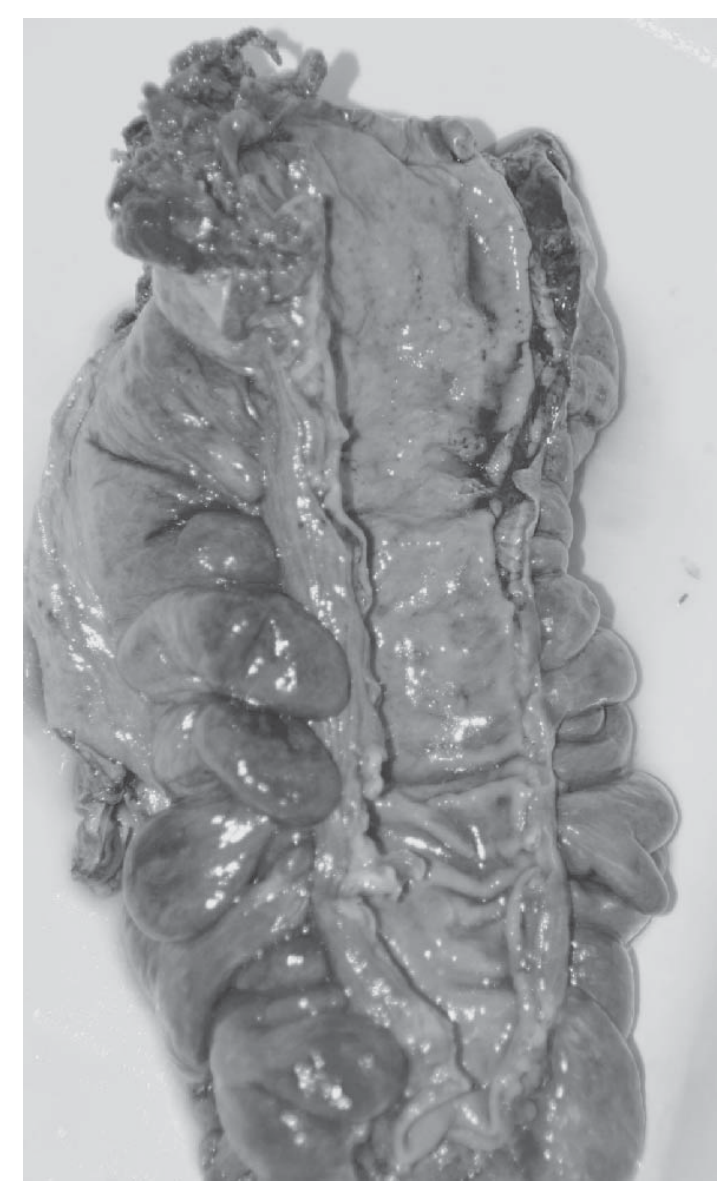

Fig. 1 
gion which was palpable on rectal examination. MR tomography revealed the presence of adjacent lobulated soft-tissue mass in the perirectal fat adjacent to the coccyx posteriorly (Fig. 1-2).

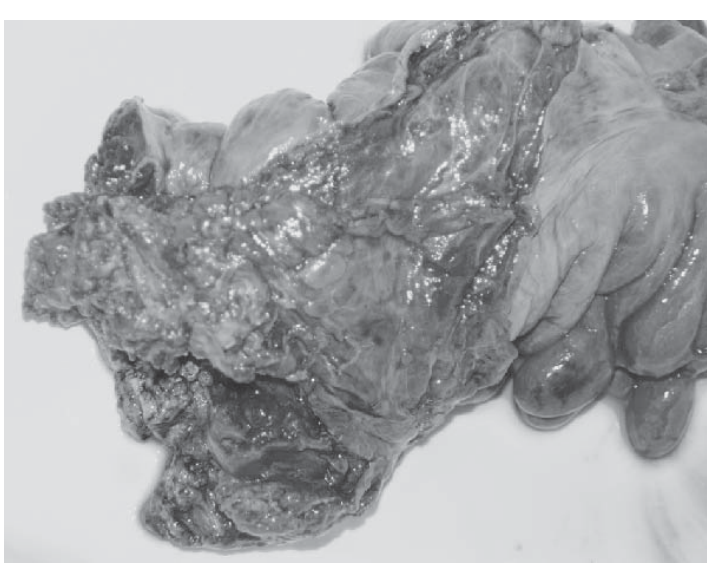

Fig. 2

After making preoperative considerations, the patient was operated on. Initially, trans-sacral approach York-Masson was applied. Due to volume of the sacral resection, the coccigeal bone and the two distal vertebras of the sacrum were removed.

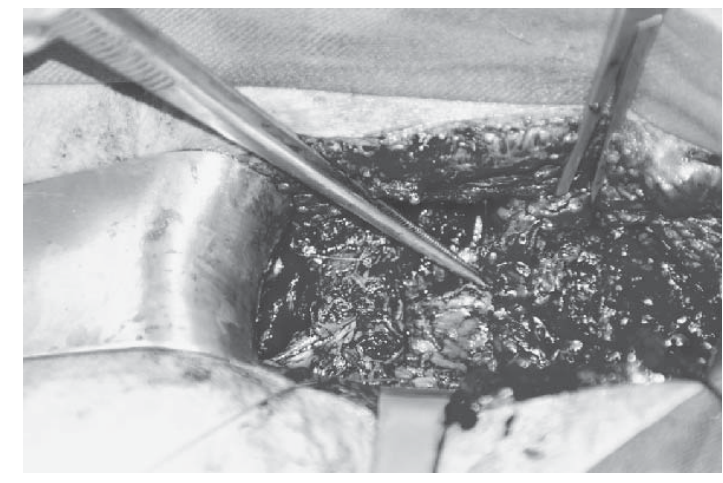

Fig. 3

Biopsy and expressed intraoperative morphological evaluation confirm the recurrent nature of the tumor mass. It was made a decision to converse the approach via laparotomy and R-0 low anterior resection of the rectum with hand-sewn anastomosis was made.

\section{DISCUSSION}

The treatment of rectal cancer has undergone a tremendous surgical evolution over the past century. Initially, in the $19^{\text {th }}$ century, the only possible safe treatment was a diverting colostomy, which then evolved first to local treatment, primarily via the Lisfranc and Kraske procedures (posterior approach), and later, in the $20^{\text {th }}$ century, to the abdominal-perineal resection popularized by Miles. Subsequently, anterior resection and low anterior resection gained a solid foothold as the most efficacious ways to treat most cancers of the rectum. In the past 3 decades, transanal excision has reemerged as a popular treatment option for T1 and selected $\mathrm{T} 2$ rectal adenocarcinomas, allowing less morbidity for early cancers. The selection criteria for this treatment have often included mobile tumor, size $<4 \mathrm{~cm}$, favorable histology without lymphovascular invasion, and anatomic accessibility with the ability to achieve 1-cm circumferential margins. Although the use of transanal excision for $\mathrm{T} 1$ rectal cancer increased from $26 \%$ to approximately $44 \%$ between 1989 and 2003, multiple recent retrospective studies have suggested that locoregional recurrence after this procedure is as high as $18 \%$ for $\mathrm{T} 1$ cancers and $47 \%$ for $\mathrm{T} 2$ cancers. Of interest, limited available prospective data reveal much better results (4-5\% locoregional recurrence rate for T1 and 14-16\% for T2). Much of the apparent discrepancy is due to patient selection, which is far more rigid in prospective trials. Conflicting data also exist as to how this outcome affects overall survival, although surgical salvage averages approximately $50 \%$ with close follow-up. The perspective topics that will be discussed in the future could be the surgical evolution of rectal cancer, best patient selection criteria for transanal excision versus more radical operation, utility and effect of adjuvant therapy in early-stage rectal cancer, current trends in the treatment of early-stage rectal cancer, and current early-stage rectal cancer trials.

\section{REFFERENCES}

1. Grigg M, McDermott FT, Pihl EA, Hughes ES. Curative local excision in the treatment of carcinoma of the rectum. Dis Colon Rectum 1984; 27:81 3.

2. Nivatvongs S, Wolff B. Technique of per anal excision for carcinoma of the low rectum. World $J$ Surg 1992; 16:447_50.

3. O Brien PH. Kraske s posterior approach to the rectum. Surg Gynecol Obstet 1976; 142:412_4.

4. Mason AY. Surgical access to the rectum: a trans-sphincteric exposure. Proc R Soc Med 1970; 63:91_4.

5. Winde G, Nottberg H, Keller R, Schmid KW, Bunte H. Surgical cure for early rectal carcinomas (T1): transanal endoscopic microsurgery vs. anterior resection. Dis Colon Rectum 1996; 39:969_76.

6. Hermanek P, Gall FP. Early (microinvasive) colorectal carcinoma. Pathology, diagnosis, surgical treatment. Int J Colorectal Dis 1986; 1:79_84.

7. Morson BC. Factors influencing the prognosis of early cancer of the rectum. Proc R Soc Med 1966; 59:607_8.

8. Nascimbeni R, Burgart LJ, Nivatvongs S, Lars on DR. Risk of lymph node metastasis in T1 carcinoma of the colon and rectum. Dis Colon Rectum 2002; 45:200_6.

9. Sitzler PJ, Seow-Choen F, Ho YH, Leong APK. Lymph node involvement and tumor depth in rectal cancers: an analysis of 805 patients. Dis Colon Rectum 1997; 40:1472_6. 
Local excision for early rectal cancer - is it proper surgical decision?

10. Hojo K, Koyama Y, Moriya Y. Lymphatic spread and its prognostic value in patients with rectal cancer. Am J Surg 1982; 144:350_4.

11. Saclarides TJ, Bhattacharyya AK,

Britton-Kuzel C, Szeluga D, Economou SG. Predicting lymph node metastases in rectal cancer.

Dis Colon Rectum 1994; 37:52_7.
12. Gall FP. Cancer of the rectum: local excision. Int J Colorectal Dis 1991; 6:84_5.

13. Ganai S., P. Kanumuri, R.S. Rao, A. I. Alexander, Local Recurrence After Transanal Endoscopic Microsurgery for Rectal Polyps and Early Cancers Ann. Surg. Oncol. Vol. 13, No. 4, 2006 